DOSSIÊ TEMÁTICO: Vitalidade do sujeito e poder de formação: narrativas autobiográficas em diálogo

\title{
REFLEXIVIDADE NARRATIVA E PODER AUTO(TRANS)FORMADOR
}

\author{
NARRATIVE REFLEXIVITY AND SELF (TRANS)FORMING POWER
}

\section{LA REFLEXIVIDAD NARRATIVA Y PODER AUTO(TRANS)FORMADOR}

\author{
Maria da Conceição Passeggi \\ Universidade Federal do Rio Grande do Norte - Brasil \\ Universidade Cidade de São Paulo - Brasil
}

\begin{abstract}
Resumo: As abordagens biográficas em educação, malgrado sua diversidade, têm como pressuposto comum o poder transformador da ação de narrar a experiência vivida. Admitem que a reflexividade narrativa propicia à pessoa que narra a possibilidade de dar sentido ao que antes não tinha $\mathrm{e}$, ao ordenar narrativamente os acontecimentos, ela (re)constrói outra versão de si e de sua formação. Uma das grandes inquietações da pesquisa consiste em examinar os modos como a ação de linguagem permite operar versões provisórias de si e da experiência narrada. O objetivo do artigo é contribuir para os estudos sobre a reflexividade narrativa como capacidade humana de operar com a linguagem essas versões de si e seu poder auto(trans)formador. Discutirei as noções de autobiografização e de heterobiografização na articulação com a reflexividade narrativa e suas incidências sobre a formação humana. Interrogo a emergência do eu e a hesitante entrada da subjetividade na pesquisa qualitativa, adotando a perspectiva defendida por Dilthey (2010), que considera inseparáveis os vínculos entre a vida, a experiência vivida e a ciência. A vitalidade do sujeito é aqui estudada com base nas noções de sujeito empírico, sujeito epistêmico e sujeito autobiográfico, enquanto dimensões da subjetividade, que se constituem pela reflexão narrativa nos processos de produção e recepção de narrativas da experiência.
\end{abstract}

Palavras-chave. Formação. Reflexividade narrativa. Subjetividade.

\begin{abstract}
Biographical approaches in education, despite their diversity, have as a common assumption the transforming power of the action of narrating the lived experience. They admit that narrative reflexivity gives the person who narrates the possibility of giving meaning to what he did not have before and, by ordering the events, he (re)constructs another version of himself and of his formation. One of the great concerns of the research consists in examining the ways in which the action of language allows one to operate provisional versions of oneself and of the narrated experience. The objective of the article is to contribute to the studies on narrative reflexivity as a human capacity to operate these versions of self and its formative power with language. I will discuss the notions of autobiography and heterobiography in the articulation with narrative reflexivity and its incidences on human formation. I question the emergence of the self and the hesitant entry of subjectivity into qualitative research, adopting the perspective advocated by Dilthey (2010), who considers inseparable the links between "life, lived experience and science". The vitality of the subject is considered based on the notions of empirical subject, epistemic subject and autobiographical subject, as dimensions of subjectivity, which
\end{abstract}


are constituted by narrative reflection in the processes of production and reception of narratives of experience.

Keywords. Training. Narrative reflexivity. Subjectivity.

Resumen: Los enfoques biográficos en la educación, a pesar de su diversidad, tienen como supuesto común el poder transformador de la acción de narrar la experiencia vivida. Admiten que la reflexividad narrativa de la persona que narra le permite dar sentido a lo que no tenía antes y, al ordenar narrativamente los eventos, (re)construye otra versión de sí misma y de su formación. Una de las grandes preocupaciones de la investigación consiste en examinar las formas en que la acción del lenguaje permite operar versiones provisionales de uno mismo y de la experiencia narrada. El objetivo del artículo es contribuir a los estudios sobre la reflexividad narrativa como capacidad humana para operar con el lenguaje estas versiones del yo y su poder formativo. Discutiré las nociones de autobiografía y la heterobiografía en la articulación con la reflexividad narrativa y sus incidencias en la formación humana. Cuestiono la emergencia del yo y la vacilante entrada de la subjetividad en la investigación cualitativa, adoptando la perspectiva propugnada por Dilthey (2010), que considera inseparables los vínculos entre la vida, la experiencia vivida y la ciencia. La vitalidad del sujeto se considera a partir de las nociones de sujeto empírico, sujeto epistémico y sujeto autobiográfico, como dimensiones de la subjetividad, que están constituidas por la reflexión narrativa en los procesos de producción y recepción de las narrativas de la experiencia.

Palabras clave. Formación. Reflexividad narrativa. Subjetividad.

\section{Na continuidade de reflexões anteriores}

A construção identitária ao que parece não consegue ir adiante se não há capacidade de narrar.

Jerome Bruner (2014, p. 97)

As abordagens biográficas em educação ${ }^{1}$ têm em comum dois pressupostos fundadores que convém lembrar para começar. O primeiro é o de que a ação de narrar e de refletir sobre as experiências vividas, ou em devir, permite dar sentidos ao que aconteceu, ao que está acontecendo, ao que pode mudar ou permanecer inalterável, mas também ao que poderia ter acontecido e por quais razões. Todas essas opções de temporalidade devem ser consideradas como possibilidades abertas, o que revela ao mesmo tempo a complexidade da narração e seu poder de auto(trans)formação. O segundo pressuposto é o de que nesse ato de linguagem, a pessoa que narra reconstitui uma versão de si ao repensar suas relações com o outro e com o mundo da vida. São muitas as operações cognitivas, volitivas ou involuntárias, envolvidas na

\footnotetext{
1 Incluímos nas abordagens biográficas a Biographieforschung, de tradição alemã; a Biographical research, desenvolvida na Inglaterra; a Investigación biográfico-narrativa, na Espanha e países da América Latina de língua espanhola; a Recherche biographique, na França, a Narrative inquiry, no Canadá e a Pesquisa (auto)biográfica, no Brasil (Passeggi, 2020).
} 
prática cotidiana de narrar e ouvir histórias, mas raramente percebemos a complexidade dessas atividades eminentemente humanas. E por mais que esses pressupostos tenham, ao longo da história, se tornado objeto de compreensão filosófica, histórica, sociológica, educativa, psicológica, ainda maior é o interesse de dar continuidade às reflexões iniciadas e em andamento.

O que segue tem como base que "o eu é produto de nosso contar e não uma essência a ser perscrutada nos recônditos da subjetividade", como afirma Bruner (2014, p. 96). A vida do "eu" está, portanto, inextricavelmente vinculada a esse ato corriqueiro de narrar. Isso se evidencia quando certas neuropatias, tais como a síndrome de Korsakoff e o mal de Alzheimer, comprometem seriamente as possibilidades de narrar, que Bruner denomina de disnarrativia ou desnarrativização. Pineau e Le Grand (2012, p. 21) falam de "um grau zero" das histórias de vida, que se caracteriza pela privação de expressão pessoal, no caso já citado de processos amnésicos, em que as pessoas atingidas vão aos poucos perdendo a consciência dessa privação, e em situações em que essa privação é intencional e visa a despersonalização do indivíduo. O caso citado pelos autores (2012, p. 21) é o do escritor soviético, Alexander Soljenitsin, no seu livro Arquipélago de Gulag (1974): "Sequer estamos certos de ter o direito de relatar esses acontecimentos de nossa própria vida". Outro grau zero é o do apagamento do "eu" pela ausência de fatos pessoalmente vividos no imenso universo da História, do discurso científico, filosófico, cultural. Para os autores (2012, p. 22), "uma crise é necessária para que o sujeito possa abandonar esse patrimônio e ter coragem para começar, não apenas a dar voz ao 'eu', mas também a refletir, fazendo-o trabalhar, selecionar e conjugar, na primeira pessoa, as palavras e os momentos herdados".

O paradoxo está na crucial importância do eu para a vida humana e essa entrada proibida, ou hesitante, da subjetividade no discurso científico. Essa é uma das questões inquietantes para as abordagens biográficas. Contra esse apagamento, Wilhelm Dilthey (18331911) proporá como base do paradigma compreensivo nas ciências humanas, a estreita relação entre "a vida, a experiência vivida e a ciência" (DILTHEY 2010, p. 95). É o que lembra DeloryMomberger (2005, p. 36, tradução nossa, grifos da autora).

Dilthey coloca no centro de sua reflexão sobre a ciência histórica, as modalidades pelas quais o homem se apropria de sua própria vida, fazendo da reflexividade autobiográfica o paradigma do 'compreender' (Versthehen) e da autobiografia o modelo hermenêutico 'das ciências humanas'.

Narrar as próprias experiências - autobiografização - e aprender com a história das experiências de outrem - biografização e heterobiografização - fazem parte de nossa 
humanidade, nos caracteriza como seres pensantes, capazes de sentir, inferir e expressar emoções, razões, desejos, intencionalidades. De modo que a privação da narrativa de si, e por conseguinte do 'eu', seja ela provocada por uma patologia, seja por processos ideológicos e políticos, nos destitui de nossa humanidade.

O objetivo deste artigo é contribuir para os estudos sobre a vitalidade do sujeito e o poder de formação de narrativas autobiográficas, abordados neste dossiê, tomando como objeto de estudo a reflexividade narrativa, entendida como a capacidade de o sujeito operar com diversas linguagens para se constituir um si mesmo, ao tempo em que dá sentido às suas experiências, às suas aprendizagens e até mesmo reconhecer seus fracassos nessas tentativas. Essa capacidade humana e seu poder de formação é central nos processos constitutivos da subjetividade. Entendemos, portanto, que uma das grandes inquietações das abordagens biográficas consiste em saber como examinar essa reflexividade narrativa, enquanto uma ação de linguagem, suscetível de gerar versões provisórias de si e da consciência histórica. Dela dependendo a atividade do sujeito, enquanto ser-interpretante, de dar sentido à vida, reinventar a percepção de si, do outro e do mundo, do que é e do que poderia ter sido.

Discutirei inicialmente as noções de autobiografização e de heterobiografização na articulação com a reflexividade narrativa e suas incidências sobre a formação humana. Interrogo, em seguida, a emergência do eu, a vitalidade do sujeito com base nas noções de sujeito empírico, sujeito epistêmico e sujeito autobiográfico, enquanto dimensões da subjetividade, que se constituem pela reflexão nos processos de produção e recepção de narrativas da experiência.

\section{A reflexividade narrativa nos processos de autobiografização e heterobiografização}

A autobiografia é um gênero curioso, é a história que nos propõe um narrador aqui e agora sobre um protagonista que traz seu nome e que existia lá e então, a história termina no presente, quando o protagonista se confunde com o narrador.

Jerome Bruner ${ }^{2}$

A noção de reflexividade narrativa, que desejamos discutir aqui, está subentendida na análise que faz Bruner (1991) da autobiografia como um gênero discursivo na epígrafe acima. Para o autor, o que caracteriza a autobiografia é esse desdobramento da pessoa que narra em duas instâncias discursivas: a de protagonista e a de narrador. Com efeito, uma primeira aproximação da reflexividade narrativa concerne esse desdobrar-se que creditamos a uma

\footnotetext{
2 Jerome Bruner, 1991, p.130, grifos do autor.
} 
disposição humana e que acontece no ato singular de narrar e de refletir sobre experiências vividas. Assim, trata-se, em primeiro lugar, de se conceber a reflexividade narrativa como essa possibilidade de desdobramento da pessoa que narra em três instâncias narrativas: a de narradora, a de protagonista e a de autora da história narrada. Nesse sentido, é na elaboração de narrativas autorreferenciais, que esse desdobramento acontece, ou seja, naquelas em que a pessoa que narra se refere a ela mesma na primeira pessoa - "Eu nasci em 1920" - ou ainda na terceira pessoa - "Naquele momento, ele não se compreendia ainda" -, recurso literário utilizado para fugir do "eu" (auto). O que importa, como afirma Bruner (op.cit.), é o trabalho de reflexão sobre um protagonista que existia lá e então e que tem o nome de quem narra. Ainda que esse nome seja fictício, ele marca a mesmidade ${ }^{3}$. Por outro lado, importa que a história termine no presente - no aqui e no agora - fazendo coincidir protagonista, narrador e autor $^{4}$ que se trate de um ponto final na história escrita, ou um sinal, na oralidade, que a história terminou: “Foi assim que aconteceu!". É essa possibilidade de desdobramento do uno em três instâncias narrativas - autor, narrador, personagem - que caracteriza o processo de autobiografização, no qual presente, passado e devir se entrelaçam, qualquer seja sua natureza - escrita, oral, pictórica, gestual... - qualquer que seja a sua denominação: narrativas de si, escrita de si, memorial, autobiografia, diário...

Nesse sentido, a autobiografização se diferencia de dois outros construtos, o de biografização e o de heterobiografização, enquanto ações de linguagem de grande potencialidade para se examinar a reflexividade narrativa, assim como se operacionalizam versões provisórias de si, do outro e do mundo. Os estudos desenvolvidos por Christine DeloryMomberger (2008, 2012, 2019), Peter Alheit (2014, 2021), Alheit e Daussien (2006) nos ajudam a conceber as noções de biografização e de heterobiografização como um trabalho biográfico da pessoa que narra.

É importante sinalizar que na revisão da literatura na área, encontramos preferencialmente as noções de biografização, de heterobiografização e que se faz raramente referência ao conceito de autobiografização. Em 2019, no livro organizado por DeloryMomberger - Vocabulário das histórias de vida e da pesquisa biográfica ${ }^{5}$-, encontram-se entradas para biografização e heterobiografização e não para autobiografização. Existem duas entradas para autobiografia, uma no campo da literatura, escrita por Sébastien Hubier e outra

\footnotetext{
${ }^{3}$ A noção de mesmidade (Ricœur, 1999) se refere aqui a traços sociais e institucionalmente reconhecidos da pessoa (seu nome, data de nascimento, filiação etc.).

${ }^{4}$ Cf. Passeggi, 2016.

${ }^{5}$ Título em francês: Vocabulaire des histoires de vie et de la Recherche biographique.
} 
no campo da pesquisa biográfica, escrita por Peter Alheit. Essa preferência se dá pela força do conceito de autobiografia em literatura, razão pela qual, também prefiro substituí-lo por narrativa autobiográfica, por ser mais amplo e incluir as autobiografias literárias. $\mathrm{O}$ que se observa é que quando se trata de autobiografia, a discussão gira globalmente em torno de verdade, ficção, autoficção, narcisismo, ilusão, questões de menor interesse para nossos propósitos.

Há, assim, um evitamento do "eu" (auto). A novidade no Vocabulário é a noção de "automedialidade", em que o "auto" ressurge numa entrada escrita por Delory-Momberger e Bourguignon (2019, p. 36-39). O que é posto em evidência pelos autores é a noção de medium (meio) que dá origem à “medialidade”. O medium deve ser entendido como o material utilizado - tela, luz, argila, ferro, cor, imagem, por exemplo -, não no sentido do senso comum enquanto uma materialidade passiva sobre a qual age o artista, mas como "o modo de ser artístico de um material", segundo Krajewski (2016, p. 2), citado pelos autores. Aqui, podemos voltar à etimologia do termo "auto-bio-grafia", em que a "grafia" é o medium, que impõe seu modo artístico de ser, enquanto material utilizado na elaboração da narrativa e mediante o qual se opera a passagem de um "eu virtual" (potencial) para um "eu atual” (materializado na escrita). Nesse sentido, inverte-se o que é admitido pelo senso comum, segundo o qual a vida (bíos) e eu (auto) engendram a autobiografia. $\mathrm{Na}$ perspectiva da automedalidade, é o projeto autobiográfico que é suscetível de engendrar a vida e o eu. Assim, faço minhas as palavras dos autores (2019, p. 38):

A experiência automedial abre um espaço de criação em que se encontram o movimento de uma busca sensível exercida sobre o material e sobre o 'fazer' da obra, a reflexão subjetiva que acompanha o gesto de criação e o trabalho sobre si de um sujeito agindo sobre ele-mesmo ao agir sobre os materiais segundo as formas do medium que ele pratica.

O gesto autobiográfico, automedial, faz da relação consigo mesmo um trabalho incessante de reflexão com materiais externos - linguagens, telas, sons, gestos - pelas quais e nas quais a subjetividade de quem narra se constitui. Nesse sentido, Paul Ricœur (1983, p. 113, tradução e grifos nossos) afirma: "não há experiência humana que não seja mediatizada por sistemas simbólicos, entre eles a narrativa".

O termo "biográfico" é assumido no sentido amplo de escrita da vida, e a noção de biografização, utilizada para se referir ao discurso autobiográfico. Para Delory-Momberger (2019, p. 47, grifos da autora, tradução nossa), "a categoria do "biográfico" dá [...] acesso ao trabalho de gênese socioindividual (ou processo de biografização) pelo qual os indivíduos 
perlaboram o mundo social e histórico e se produzem como seres sociais singulares." O processo de biografização corresponderá aqui ao ato de narrar a vida de outrem, diferente de si mesmo. Essa ação é usual nas pesquisas que utilizam como fontes as narrativas de si, obtidas mediante entrevistas narrativas, escritos pessoais, depoimentos, relatos de pessoas que conviveram com a pessoa biografada. Compete ao pesquisador-biógrafo criar um enredo na composição da biografia. Nesse caso, a narrativa se faz na terceira pessoa.

Em sociologia, o apagamento do eu (auto), ou o grau zero, parece ser uma opção de objetividade científica. No debate científico, há uma luta entre o nomotético, que busca depreender aspectos gerais ou universais das narrativas, e o ideográfico, que concerne ao subjetivo na história de vida. Schütze (2010, p. 210), por exemplo, assim define a pesquisa biográfica em sociologia:

\begin{abstract}
Na pesquisa biográfica no campo das Ciências Sociais predomina o interesse pelo ciclo de vida de grupos etários de uma dada sociedade (coortes) e de grupos de pessoas (agregados sociais) com determinadas características sociais (por exemplo, mulheres das classes populares) que busca muitas vezes na pesquisa encontrar traços predominantes.
\end{abstract}

Essa é também a posição de Daniel Bertaux (2012), em etnossociologia. O que importa para o autor não são propriamente as vidas das pessoas, mas as práticas sociais utilizadas nos grupos de profissionais investigados que emergem nas narrativas. Contrariamente a esses dois autores, Franco Ferrarotti (2014, p. 43, grifos nossos), ao propor o método biográfico para as Ciências Sociais, defende o uso das histórias de vida, numa perspectiva crítica, que reabilite a "subjetividade explosiva" das narrativas de si.

Devemos voltar a trazer para o coração do método biográfico os materiais primários e a sua subjetividade explosiva. Não é só a riqueza objetiva do material biográfico que nos interessa, mas também, sobretudo, a sua pregnância subjetiva no quadro de uma comunicação interpessoal complexa e recíproca entre o narrador e o observador.

É essa subjetividade que emerge mediante o trabalho autobiográfico com a linguagem ou qualquer outro instrumento semiótico que nos interessa aqui. Em textos anteriores (PASSEGGI, 2020a; 2020b), tenho insistido sobre essa entrada hesitante do eu (auto) nas pesquisas que recorrem às narrativas autobiográficas como fonte de investigação científica. Martucelli (2005) reconhece nos trabalhos atuais em sociologia, a importância de um movimento intelectual que se volta cada vez mais para o próprio indivíduo. Nessa direção, ao invés de se propor exclusivamente uma visão descendente - da sociedade para o indivíduo -, a 
tendência é se acrescentar cada vez mais nos estudos sociológicos uma visão ascendente (do indivíduo para a sociedade).

Por sua vez, a noção de heterobiografização nasce em resposta a perguntas como estas: Qual o efeito da escuta e da leitura de narrativas de outrem sobre nossa própria vida? Como captamos os sentidos que alguém atribui às experiências vividas? Para Delory-Momberger (2019, p. 89, tradução nossa), o termo "heterobiografização" foi criado "para dar conta dos processos que se realizam na escuta e na leitura de textos biográficos [e autobiográficos] e dos efeitos de compreensão e de formação que acontecem por eles".

Assim, nos formamos tanto pelas atividades de autobiografização, quanto pela escuta, leitura, de experiências alheias, nos processos de heterobiografização. A narrativa de outrem abrem universos nos quais penetramos por uma atitude de empatia e desde a mais tenra infância. Do ponto de vista da ontogênese, a heterobiografização surgiria antes do processo autobiográfico. Com efeito, uma criança de oito meses de idade reage rapidamente ao Show da Luna, seu desenho favorito, e gosta de ouvir, ver e "ler" histórias. Mais adiante, ela também aprenderá com as narrativas da mãe, ou da professora, em que ela se vê promovida ao estatuto de heroína (Marina já consegue ler), ou rebaixada ao papel de vilã (Marina nunca presta atenção).

Trata-se então de uma potente noção investigativa. É pela heterobiografização que os mitos e os ritos de instituições socializadora - família, escola, igreja, agremiações... - se criam, se impõem, se perpetuam ou morrem. É ainda mediante a heterobiografização que o universo midiático de alcance planetário forma, deforma, conforma, transforma o espírito, estimulando rituais miméticos na apropriação de gestos, imagens, ideologias que não podem muitas vezes ser refutados.

A reflexividade narrativa está, portanto, estreitamente vinculada às noções de autobiografização, de biografização e de heterobiografização, enquanto atividades que o humano desenvolve ao longo da vida e em todas as circunstâncias da vida. Mas, é importante sinalizar que se trata de uma atividade eminentemente subjetiva. Seria, portanto, quase tautológico afirmar que toda aprendizagem é autobiográfica, posto que ela se opera no serpensante, que aprende ao refletir sobre si com a história contada pelo outro (heterobiografização) com a história que ele, ou alguém, conta sobre outrem (biografização) e com a história que ele conta sobre si mesmo (autobiografização).

\section{Vitalidade do sujeito e potencialidade da reflexividade narrativa}


O crescimento intelectual implica uma capacidade de dizer a si próprio e aos outros o que se fez ou o que se vai fazer.

(Jerome Bruner, 1999, p. 22).

É, portanto nessa direção primeira de um ser-a-vir e de um ser-para que o eu se constrói como tendo-sido.

(Christine Delory-Momberger, 2008, p. 65) ${ }^{6}$.

A vitalidade e o poder de formação do sujeito, mediante a elaboração ou a escuta de narrativas, colocam em jogo a reflexividade narrativa tal como começamos a descrever. Tratase agora de focalizar o seu poder auto(trans)formador e de emancipação, que implica a noção de consciência histórica. Poder-saber-refletir-querer-emancipar-se nem sempre é assunto, sistematicamente, abordado pelas instituições destinadas à formação do indivíduo. O "expert" - ancião, professor, pesquisador, supervisor - lança muitas vezes ao acaso: "Reflita sobre o que você fez", "Você bem que poderia anotar para refletir sobre o assunto"... No caso mais específicos de instituições escolares, universitárias, observa-se que espaços de reflexão conjunta sobre a experiência profissional e pessoal tendem a se afirmar. Não faltariam razões para explicar tanto seu interesse, quanto sua ausência.

Como se sabe, no início dos anos 1980, a prática das narrativas de si emerge no âmbito da formação continuada de adultos, em países francófonos com o movimento socioeducativo das histórias de vida em formação, e nesses últimos 40 anos, atravessou variadas etapas, como sugere Pineau (2006). Mas é nos anos 1990 que os estudos sobre a formação docente se voltam para o que se denominou de "professor reflexivo", "professor-pesquisador" na sequência de estudos seminais de Donald Shön (1983) sobre o profissional reflexivo. No âmbito da lusofonia, António Nóvoa, que fez seu doutorado com Pierre Dominicé, em Genebra, um dos pioneiros das histórias de vida em formação, introduz essa perspectiva na formação docente. Esse interesse coincide com a "descoberta" das narrativas orais e escritas nas ciências humanas e sociais como "um parâmetro linguístico, psicológico, cultural e filosófico fundamental para nossa tentativa de explicar a natureza das condições de nossa existência", como tão bem analisam Brockmeier e Harré (2003, p. 526).

A pesquisa sobre narrativas da experiência e sobre seu poder auto(trans)formador se articula com duas guinadas nas ciências humanas e sociais, que se sucederam a partir de meados do século XX. Uma guinada reflexiva, desencadeada pelos movimentos sociais dos anos 1960, que obrigaram as ciências sociais e humanas, como afirma Alain Touraine (1977), a melhor escutar o que tinham a dizer as pessoas - estudantes, mulheres, negros, migrantes,

${ }^{6}$ Grifos da autora 
desempregados... -, que lutavam por seus direitos sociais e a encontrar formas de investigação suscetíveis de legitimar suas vozes em benefício de suas lutas. A guinada narrativa se desdobra sob o impulso da primeira na busca da compreensão do humano e de instrumentos de pesquisa que comtemplassem o "retorno do sujeito" e seus desafios teóricos e conceituais. Esse segundo movimento faz das narrativas pessoais a matéria-prima da investigação científica e da democratização hermenêutica um modo de compreender o que acontece nas paisagens externas e internas de quem narra.

É no encadeamento dessas duas primeiras viradas que emerge a guinada biográfica, como terceiro movimento de ruptura paradigmática. Nasce aqui um novo horizonte. O que caracteriza esse terceiro momento é o aprofundamento do olhar sobre os modos como o humano - crianças, jovens, adultos, sêniores - (re)elabora a experiência vivida e, por conseguinte, os processos de formação. Assim, para além de um método de pesquisa, as narrativas de si tornamse dispositivos pedagógicos de formação e de intervenção, o que permite falar de educação narrativa, pedagogia narrativa, narrativas pedagógicas. É nesse novo direcionamento que se desenvolverão pesquisas sobre teorias da formação em países europeus de onde se irradiará para as Américas. Ao longo dos últimos 40 anos, a guinada biográfica, pelos avanços científicos, repercussão na formação de novos pesquisadores e fóruns internacionais de debate deu origem ao que denominei em outros estudos de paradigma narrativo-autobiográfico ${ }^{7}$.

Essa terceira guinada incorpora um aspecto epistemopolítico, neologismo proposto por Pineau e Le Grand (2012), na orientação da virada reflexiva e de uma democratização hermenêutica da segunda. Tradicionalmente vinculada ao mundo do adulto, a virada biográfica focalizou prioritariamente temáticas próprias desse universo: a vida no trabalho, (re)inserção, permanência, desemprego, aposentadoria, constituição e transformação da identidade profissional, acompanhamento na formação, na prática profissional e mesmo diante da morte. $\mathrm{Na} \mathrm{Carta}^{8}$ da Associação Internacional das Histórias de Vida em Formação (ASIHVIF), elaborada e adotada nos anos 1990 pelos pioneiros, lê-se que: “A perspectiva que orienta, media e apoia as práticas da narrativa de vida é a emancipação pessoal e social do sujeito. Entende-se por emancipação a ação que tende a substituir uma relação de assujeitamento por uma relação de igualdade" (ASIHVIF, 2016, p. 177, grifos nossos). Para tanto, ainda segundo a Carta, na "prática de intervenção, a narrativa de vida permite ao sujeito, com base numa explicitação de

\footnotetext{
${ }^{7}$ Cf. Passeggi, 2020a, 2020 b.

${ }^{8}$ A tradução da Carta da ASIHVIF foi publicada no primeiro número da Revisita Brasileira de Pesquisa (Auto)Biográfica (RBPAB).

Disponível em: http://www.revistas.uneb.br/index.php/rbpab/article/view/2530/1715.
} 
seu percurso de vida, dispor dos meios necessários à tomada de consciência reflexiva e crítica, visando situar-se como ator social num projeto de ação mais lúcida e mais pertinente (Carta da ASIHVIF, 2016, p. 178, grifos nossos).

Na literatura da área, a noção de "prática de intervenção" será substituída por "pesquisaformação" ou "pesquisa-ação-formação", nos estudos de Dominicé (2000), Pineau (2005), Josso (2012), Passeggi (2016, 2020). Os traços de união entre os termos marcam a indissociabilidade entre a pesquisa, a formação e a ação. $\mathrm{O}$ conceito amplia-se na medida em que se sistematizam as aprendizagens que fazem os pesquisadores nos processos de escuta e de escrita. Nessa perspectiva, o objetivo da lógica da formação fugiria de uma lógica da educação alicerçada na "submissão" do sujeito às práticas institucionais - escolares, familiares, profissionais -, supostamente exigidas em função do "bem comum", da "produtividade" etc. É nesse sentido que o conceito de consciência história ganha todo o seu sentido.

Para Gadamer (1997, p. 316, grifos do autor),

[a consciência histórica] não é a expressão imediata da realidade vital como era a consciência antes de elevar-se vitoriosamente a uma consciência histórica. [...]. Pelo contrário, reconhece-se numa relação reflexiva consigo mesma e com a tradição na qual se encontra. Compreende a si mesma a partir de sua história. A consciência histórica é uma forma de autoconhecimento.

A consciência histórica implica um trabalho sobre si e sobre percepções do mundo para ultrapassar apropriações ingênuas da "realidade" e se elevar acima das representações herdadas ou que circulam como "verdades". Mas, como sinaliza o autor (1996), a consciência histórica tanto pode ser um privilégio, quando um fardo, como nunca se impôs a nenhuma outra geração. Com efeito, o imperativo reflexivo de uma sociedade biográfica se opõe aos processos alienantes de despersonalização ou de desresponsabilização. Diria, retomando de memória ensinamentos de Paulo Freire, que é necessário passar da tomada de consciência, que se realiza como operação mental, para a conscientização, que exige uma ação consciente no mundo. A primeira dessas ações consiste em se apropriar da palavra para pronunciá-la como ação no mundo. Assim, para que ela se realize plenamente, e se constitua um ato formativo, é preciso que ela se concretize em situações interativas e no ato de enunciação. Por essa razão, é que se diz ser um ato performativo, no sentido em que "dizer é fazer" (AUSTIN, 1990). Ao se dizer "eu prometo", faz-se uma promessa. Assim praticamos ações louváveis, ou não, com as palavras pronunciadas no mundo da vida.

O senso comum tende a confundir a narrativa de si com o movimento retrospectivo, o de se voltar para o passado. Mas, como afirma Delory-Momberger, na epígrafe acima, é nessa 
direção primeira de um "ser-a-vir" e de um "ser-para" que o "eu" se constrói como "tendosido". Esse movimento retrospectivo que se realiza na narrativa é intuitivamente associado a ela. Mas para compreendermos a vitalidade do sujeito e o poder de formação da reflexividade narrativa, é necessário considerar três movimentos: o retrospectivo, voltado para o passado; o prospectivo, que se projeta em devir, e o inspectivo, que se realiza no presente, com base no qual se examina, inspeciona-se, avalia-se o que aconteceu, poderia ter acontecido ou poderá acontecer. É bem verdade que mirar o futuro pode provocar tremores e não é sem motivos que se diz: "o futuro é incerto", “o que passou, passou", "prefiro viver o presente". No entanto, narrar é preciso! Para não enclausurar, sacralizar, o passado. Para alargar o presente. E sobretudo nos constituirmos em devir. Essas são marcas de reflexividade narrativa fundantes de nossa condição biográfica, a de seres narradores, que encadeiam, temporalmente, acontecimentos presentes, passados e futuros num enredo com começo, meio e fim, ou "sem pé nem cabeça", mas enredo...

A reflexividade narrativa põe em jogo a memória autobiográfica, aqui entendida como uma disposição humana a preservar na memória palavras, gestos, sons, sabores, perfumes.... que constituem arquivos de experiências vividas, projetadas, sonhos e impressões, que constituem nosso capital biográfico. Esse arsenal de lembranças, impressões, gostos-desgostos são acessados voluntária ou involuntariamente, mediante a capacidade humana de refletir narrativamente para dar sentido ao que é contado, descrito, explicitado.

Lehrer (2011), no livro provocador Proust era um neurocientista. Esses artistas que precederam os cientistas ${ }^{9}$, lembra que em 1911, ano em que Marcel Proust dá início a sua obra - Em busca do tempo perdido - composta por sete livros, não se tinha a menor ideia dos modos de conexão dos sentidos - paladar, visão, tato, audição, olfato - no interior do cérebro. Para Leher (op.cit.), o exame que Proust faz de suas lembranças de infância com base nas sensações experienciadas, no presente, revela o que as neurociências levaram anos para constatar. A primeira é a de que dos cinco sentidos, o paladar e o olfato são os que têm memória mais prolongada. O segundo é a da flutuação da memória, entre a impressão do vivido e o sentido que queremos, podemos, desejamos ou sabemos atribuir. O terceiro é que "o ato de rememoração nos transforma" (LEHRER, 2011, p. 139). Esses pontos, salientados pelo neurocientista, nos ajuda a pensar que a memória, a experiência vivida e a consciência de si estão intrinsecamente vinculadas à reflexividade narrativa, ou que é ela que opera essa vinculação no ato de narrar ou de escutar, ler suas próprias experiências ou as de outrem.

${ }^{9}$ Cf. LEHRER, Jonah (2011) Proust était un neuroscientifique. Ces artistes qui ont devancé les hommes de sciences. 
Para ilustrar, retomo dois exemplos completamente díspares: a narrativa da célebre madelaine de Proust e a micronarrativa de Guy, de cinco anos de idade. Para Proust, o gosto da madelaine, um bolinho amanteigado, lhe permite mergulhar na memória em busca de saber de onde vinha aquela "potente alegria" despertada pela madelaine molhada no chá: "O que ela significa? Onde apreendê-la?”. A busca de Proust é estabelecer relações entre suas sensações gustativas e olfativas, a memória e a consciência de si. Trata-se de um momento mágico que o transforma: "Eu deixava de ser medíocre, contingente, mortal [...]. É claro que a verdade que eu procuro não estava nela mas em mim" (Apud Leher, 2011 p. 132, tradução nossa).

A narrativa de Guy ${ }^{10}$ permite afirmar que a reflexividade narrativa está presente entre quatro e cinco anos de idade e que ela se expressa em narrativas mínimas ${ }^{11}$ :

- Um dia, eu cresci, aí, eu cresci desse tamanho (abrindo os braços). Foi!

A micronarrativa de Guy é então uma narrativa autobiográfica plena? Como insiste Barthes (2011, p. 19-20), narrativa, em sua imensa variedade, "ridiculariza a boa e a má literatura: internacional, transhistórica, transcultural, a narrativa está aí, como a vida". Contudo, resta saber "como dominá-las, como fundamentar nosso direito a distingui-las, a reconhecê-las em sua variedade", entre as "inumeráveis [...] narrativas do mundo". É evidente, como afirma o autor (op. cit., p. 51), que "toda narrativa é tributária de uma situação narrativa". A micronarrativa de Guy contém os "signos de narratividade" (BARTHES, 2011), apreendidos por ele nos processos de heterobiografização. Cada unidade tem uma função específica no encadeamento do enredo: "Um dia, eu cresci" (marca o começo da história); "aí," (sinaliza o desenrolar do enredo); "eu cresci desse tamanho" (marca a sua transformação); "Foi." (sinaliza o final da história, a coda). Há aqui uma sucessão de acontecimentos e de transformações, da passagem de um estado inicial (eu era um bebê) ao estado atual (sou um menino desse tamanho).

Para William Labov, citado por Prince (2012), as histórias sem interesse desencadeiam um redondo “E aí?!". Uma boa narrativa, suscita ao contrário o interesse, o espanto, ou qualquer outra emoção pelo acontecimento narrado: Realmente!? Assim a frase de Guy é uma narrativa. Em primeiro lugar, é uma boa narrativa, pois ela não suscita um "E aí?", mas "Foi mesmo, Guy?!’. Em seguida, como afirma Bruner (1991), as narrativas autobiográficas se concluem

${ }^{10}$ Passeggi, M.C. "Narrativas infantis: o que contam as crianças sobre as escolas da infância" (processo ${ }^{\circ}$ 401519/2011-2, 2012- 2015); "Narrativas da infância. A criança como agente social" (processo no 311269/20133. 2014-2019; "Narrativas da infância: o que contam as crianças sobre a escola e os professores sobre a infância" (processo no 462119/2014-9); "Narrativa, educação e saúde: crianças, família e professores entre o hospital e a escola" (processo no 443695/2018-0); (2); "Narrativas, educação, saúde: epistemologia e métodos da pesquisa (auto)biográfica com crianças". (processo n 307063/2019-4).

${ }^{11}$ Cf. Prince (2012). 
quando o autor, o narrador e o personagem coincidem no final da história. Em terceiro lugar, a compreensão de uma (micro)narrativa é tributária do contexto em que ela é produzida. Assim, facilmente, encontramos no contexto os elementos que sustentam a história do crescimento de Guy e o sentido que tem para ele dizer como cresceu. A ênfase final: "Foi!" sinaliza que ele diz a "mais pura verdade". "Eu sei que já não sou mais um bebê. Pois um dia eu cresci. E foi assim que me tornei esse menino desse tamanho que você está vendo agora."

É, portanto, pela narração e na narração, produzida pelo humano - crianças, jovens, adultos, sêniores - que ele se concebe, se percebe em auto(trans)formação, mediante movimentos retrospectivos, inspectivos, prospectivos e interativos que ocorrem durante a narração.

Desejo retomar o pensamento de Bruner (2014) sobre essa predisposição humana para narrar sua própria experiência e insistir com Delory-Momberger (2005, p. 14, grifos da autora) que o autobiográfico se enraíza nessa atitude fundamental do ser humano "que consiste em configurar narrativamente a sucessão temporal de sua experiência". Os processos de reflexividade narrativa se realizam mediante um duplo trabalho com a linguagem. Um trabalho de interpretação para dar sentido às experiências vividas e narradas, e um trabalho de textualização, pelo qual se produz um texto, oral ou escrito, que organiza narrativamente os acontecimentos da própria história (autobiografização), da história que escreveu, escreveram, sobre outrem (biografização) e do que se apreendeu com a narrativas de outrem (heterobiografização).

\section{A tripla dimensão da subjetividade e o poder da reflexividade narrativa}

Em um webnário recente, a convite do Povo de Clio e do Grupodocci, insisti em querer saber de onde vinha uma pergunta que surgiu "como num clarão": "Quem tem medo da singularidade?", com a qual intitulei minha fala. Percebi que estava associada ao título de um filme de 1966, Quem tem medo de Virgínia Woolf?, dirigido por Mike Nichols, com Elizabeth Taylor e Richard Burton. Percebi, então, que a pergunta estava sobretudo associada à Virginia Woolf, pela leitura do livro de Jonah Lehrer (2007), já mencionado, em que o autor analisa as obras de oito artistas modernistas - escritores compositores, pintores... -, entre eles a de Virginia Woolf (1822-1941) e a de Marcel Proust (1871-1922), que viveram entre meados do século XIX, quando nasce as ciências positivistas, e meados do século XX; eram, portanto, contemporâneos de Dilthey (1833-1911) e de Einstein (1879-1955). A escolha desses modernistas se deve à extrema precisão de suas intuições descritas em suas obras, e que para 
Lehrer antecipa as descobertas das neurociências sobre o funcionamento do cérebro com relação à linguagem, à memória, às sensações.

Em suas obras, impregnadas da efervescência do espírito científico da época, esses artistas se expressam, se rebelam, com a liberdade que a arte permite ao processo de criação e de invenção. Para Virgínia Woolf (1822-1941), cuja escrita introspectiva está enraizada em sua própria experiência, escrever lhe permitia dar forma aos momentos de depressão, que a levaria ao suicídio aos 59 anos de idade. Para Lehrer (2012), o interesse da escrita de Woolf é o de ajudar a compreender a emergência do $\mathrm{Eu}$, o que nos interessa particularmente aqui. Vivendo com medo de seu próprio espírito e de sua doença, Woolf escreve em seu diário: "Minha própria psicologia me interessa, eu tenho a intenção de registar sistematicamente meus altos e baixos para minha própria informação. Assim, objetivadas minha dor e minha vergonha diminuirão instantaneamente". Excertos como esses são também reveladores do espírito científico. Woolf estudava biologia para compreender sua doença: "Eu pego no meu cérebro como numa pera, para ver se ele está maduro" (apud Lehrer, 2012).

E então, como emerge o Eu? Ele surge do conjunto de lembranças anárquicas, sensações confusas. Para V. Woolf, em muitas passagens de sua obra, o eu emerge por um ato de atenção voluntária sobre algo que lhe desperta curiosidade, como por exemplo: um raio de luz fugaz transpassando a água límpida. Esse ato de atenção do qual nos fala Woolf é o que nos permite retomar o pensamento de Dilthey (2010) sobre a "reflexividade autobiográfica". Ou seja, Virginia Woolf se debruça sobre as sensações que chamam sua atenção e as descreve com detalhes, assim fazendo, ela se (re)conhece como um eu. Buscar compreender as próprias sensações é algo determinante para a consciência de si. São gestos como esses que busco apreender como marcos da reflexividade narrativa, centrados na experiência vivida.

Mas se para Woolf essa consciência emerge do trabalho minucioso, para outros, a consciência de si surge como um clarão, uma epifania. Retomo um excerto de David Hume (1711-1776), citado por Delory-Momberger (2014, p. 202, grifos nossos) e outro da autobiografia de Emmanuelle Laborit (1993), por sua semelhança. Em seu Tratado da natureza humana, Hume narra que a consciência de si emerge na infância como um clarão, essa revelação de se perceber como um eu durará para sempre:

Certa manhã, quando ainda bem criança, estava eu à porta da casa e olhava para a esquerda em direção ao fogo quando, subitamente, a intuição íntima: Eu sou um eu (Ich bin ein Ich), brilhou como um relâmpago vindo do céu; seu brilho desde então ficou presente em mim; meu eu tinha se percebido a si mesmo pela primeira vez e para sempre. 
Surda profunda, Emmanuelle Laborit (1993, p.70, tradução minha) admite que se descobre como um "Eu", aos sete anos de idade, também como num clarão ao adquirir a língua de sinais.

Eu tinha uma definição de mim do tipo: 'Emmanuelle, você não escuta'. Depois de ter compreendido o 'eu', 'Eu me chamo Emmanuelle', naquela noite, eu compreendi, como num clarão: 'Eu sou surda'. Naquele dia, eu cresci em minha mente. Enormemente. Eu me torno um ser humano dotado de linguagem. Os ouvintes utilizam a voz. Eu utilizo minhas mãos. Eu tenho simplesmente outra língua.

O "eu" é, pois, uma obra da linguagem. Uma arte criada entre rememoração e imaginação. O problema para as neurociências é a fragmentação, a evanescência do eu. "O eu tal como o sentimos é completo, mas a ciência só pode ver as partes”, diz Lehrer (2012, p. 293), e continua argumentando com Noam Chomsky: “É bem possível - amplamente provável, poderíamos imaginar - que nós aprendemos mais sobre a vida humana e a personalidade nos romances do que na psicologia [...] Se a ciência nos decompõe, a arte nos recompõe”. A arte, sob as mais diversas modalidades, escrita, literatura, poesia, música, pintura... nos permite agregar fragmentos de nossas experiências sensoriais - imagens, sons, perfumes, sabores - que nos escapam, fogem. A arte de narrar eterniza esses fragmentos do eu sob formas de uma narrativa automedial.

Em textos anteriores ${ }^{12}$, propus que a subjetividade se realizava em três instâncias que denominei de sujeito empírico, sujeito epistêmico e sujeito autobiográfico. Entendo, ao ler textos que retomam essa proposta, que não fui suficientemente feliz, por isso retomarei aqui essas três noções, e mais explicitamente a de sujeito da experiência.

Meu foco de interesse é conceitualizar o sujeito autobiográfico, por uma razão que me parece crucial: o sujeito autobiográfico é concebido como instância narrativa que se constitui na linguagem e pela linguagem no ato de narrar. No entanto, a valorização do pensamento epistêmico e a negligência do pensamento anárquico, efêmero e vívido, gerou a dicotomia tradicional entre o objetivo (lógico) e o subjetivo (alógico), que entendo como uma separação didática. Essa separação seria melhor compreendida se ela fosse considerada como um continuum e não como uma oposição. O pensamento lógico está inextricavelmente ligado ao pensamento alógico, eles se alternam em movimentos regressivos e progressivos no serpensante-reflexivo.

${ }^{12}$ Cf. Passeggi, 2014; Passeggi, 2016. 
A subjetividade estaria constituída por três dimensões. A primeira dimensão é a do sujeito empírico (autor), que vive a experiência da vida enquanto sujeito de carne e osso, que tem nome, idade, etnia, gênero, a quem se pode imputar a autoria do texto narrativo. É ele que dá início a narrativa e põe o ponto final. Durante a narração, o sujeito empírico (autor) é invadido por pensamentos alógicos que resultam da experiência vivida, anárquica, caótica, feita de fragmentos, de pedaços de mosaicos, com os quais é preciso compor uma figura de si, um enredo, que vai na direção da reinvenção da realidade. $\mathrm{O}$ eu (auto) se debate com a grafia, o medium que se impõe com seu modo artístico de ser, próprio a qualquer material. E assim como o mármore, a argila, a tela e som impõem seu modo de ser ao escultor, ao pintor, ao músico, a grafia se impõe ao autor.

A segunda dimensão é a do sujeito epistêmico, que vive a experiência da racionalidade na busca de coerência, explicações para dar sentido à vida. Essa atividade é a que lhe permite objetivar, compreender o que acontece e o que lhe acontece no mundo da vida e no mundo do texto. Mediante esse trabalho reflexivo se configura a terceira dimensão da subjetividade, aquela em que vive e mora o sujeito autobiográfico, que metaboliza o que as duas outras dimensões da subjetividade - existencial e racional - lhe oferecem. O sujeito autobiográfico se apresenta como desdobramento do sujeito empírico que toma a si mesmo, como o objeto de reflexão. E mediante o uso da linguagem - oral, escrita, digital, gestual, icônica... - transformase em narrativa, poesia e história. $\mathrm{O}$ que pode parecer desencorajante é que a natureza do sujeito autobiográfico não é a vida (bíos), mas a linguagem (grafia), e que vive, portanto, sob a forma de uma narrativa, de um texto, em que se vê como um "eu" e se analisa como um outro. É esse si-mesmo - o eu pensado e examinado - que, em síntese, surge e vive na efemeridade da narração, como ato discursivo, e permanece na eternidade da narrativa, enquanto produto material, resultante da narração.

$\mathrm{Na}$ instância da narração, o sujeito autobiográfico é indissociável do sujeito empírico (autor, de carne e osso) e do sujeito epistêmico (racional, lógico). Assim como do personagem que existia lá e então e que está sendo aqui e agora. Quando autor põe o ponto final na narrativa, o sujeito empírico (o autor) se separa do sujeito autobiográfico (narrador), que permanece no mundo do texto, enquanto o autor se retira para compor outras narrativas.

É pela atividade narrativa que o sujeito autobiográfico (o narrador) religa o que as duas dimensões da subjetividade que a ciência moderna separou. Ou seja, a dimensão do sujeito epistêmico, racional, lógico, objetivo, e a dimensão do sujeito empírico, de carne e osso, existencial, que vive as emoções de seu pensamento anárquico, errante, marcado por lembranças confusa, indefinidas. Resta agora (re)conceitualizar o sujeito da experiência. A 
metáfora é a da folha de papel ou a da moeda com sua dupla face. O sujeito da experiência será sempre o anverso de cada uma das três outras dimensões. Não se poderia cortar uma sem cortar a outra.

Quando insistimos sobre as três dimensões da subjetividade a intenção é de valorar a palavra de quem narra: do eu (auto). De modo que a dimensão do sujeito empírico, de carne e osso, é vivida de igual modo pelo humano quer se trate de um adulto, uma criança, de uma pessoa letrada ou privada do letramento. A segunda dimensão, a do sujeito epistêmico, corresponde a indagações, a busca de coerência para dar sentido à vida, o que deve ser concebido em qualquer idade e em todas as circunstâncias da vida. A terceira dimensão, a do sujeito autobiográfico, que integra os dois outros, é importante para o debate sobre a instância discursiva pois é nela que se dá a constituição de uma identidade narrativa, sempre provisória, como sugere Ricœur (1999), mas que resulta da reflexividade narrativa, quer se trate de crianças, jovens ou adultos, cada pessoa se constitui como sujeito ao longo da vida, reconstruindo permanentemente sua identidade narrativa, nos processos de autobiografização, de biografização e de heterobiografização.

Nessa direção, cumpre melhor analisar a legitimidade da palavra da criança, por exemplo, comumente invalidada em função da "insuficiência" de seus modos de se expressar e por se considerar que suas narrativas estão transpassadas mais pela ficção do que pela razão, o que leva a atribuir à criança um estatuto de sujeito epistêmico-em-devir, negando-se a ela a capacidade que ela tem de refletir sobre a própria experiência, enquanto sujeito autobiográfico e do autoconhecimento. É muito timidamente que se dá ao sujeito autobiográfico o direito de cidadania no mundo científico, marcado pelas mais severas restrições residuais de um paradigma que associa a subjetividade e a singularidade à ficcionalidade, à irracionalidade, dissociando "vida, experiência vivida e ciência" como propõe Dilthey (2010), o que nos parece mais justo para se considerar modos de se conceber a condição biográfica do humano de forma mais ampla e mais justa.

\section{Considerações finais}

Para concluir, direi que a reflexividade autobiográfica, subjacente ao paradigma compreensivo nas ciências humanas e sociais, apresenta-se como um dos conceitos-chave das pesquisas que recorrem às narrativas de si em todas as suas modalidades. Ela dá conta da vitalidade do sujeito e do poder auto(trans)formados das narrativas de si, com grandes 
potencialidades para os estudos da memória, dos processos de aprendizagem, de construção identitária, enfim da formação humana.

Quem não seria capaz de confirmar que a sensação despertada por um perfume subsiste na memória quando todo o passado desvanece? O que há de mais subjetivo do que essa memória autobiográfica e as sensações enlaçadas pela reflexividade narrativa? Assim, o sujeito, no ato de narrar, enlaça a razão que quer dar sentido à experiência vivida, à emoção dessa alegria, dessa dor corpórea, e à consciência de si, que anima o corpo, no sentido de lhe dar alma. Esse esforço cognitivo sobre o sensível, à maneira de Proust, evidencia que a reflexividade narrativa se realiza mediante o trabalho com as linguagens - naturais, racionais, poéticas, sinestésicas... - e que o Eu necessita delas para existir.

De modo que nós não pegamos a agulha e a linha para bordar nossa história, nós somos a agulha, a linha e o bordado que fazemos sobre o tecido da vida. Mas será que o poder de se constituir ao tecer memórias e projetos em devir são privilégios do adulto, de grandes escritores? Ou somos todos, em diferentes idades, cientistas potenciais? Talvez sim, se concebermos o humano como agente suscetível de transformar as experiências vividas em conhecimento, de se dotar de aprendizagens necessárias para viver uma vida boa, para conceber o bem, desfrutar do belo e propor o que é justo, ao conjugar razão e emoção, vida e experiência vivida, arte e ciência, para falar da vitalidade do sujeito e de seu poder de auto(trans)formação.

\section{REFERÊNCIAS}

ASIHIVIF. Carta da ASIVIF. Nossa carta. Trad. Maria da Conceição Passeggi. Revista Brasileira de Pesquisa (Auto) Biográfica, Salvador, v. 01, n. 01, p. 177-179, jan./abr. 2016.

AUSTIN, J.L. Quando dizer é fazer: palavras e ação. Tradução Danilo Marcondes de Souza Filho. Porto Alegre: Artes Médicas, 1990.

BARTHES, Roland et al. Análise estrutural da narrativa. Trad. Maria Zélia barbosa Pinto. Petrópolis, RJ: Vozes, 2011.

BRUNER, Jerome. Fabricando histórias. Direito, Literatura, Vida. Tradução Fernando Cássio. São Paulo: Letra e Voz, 2014.

BRUNER, Jerome. Para uma teoria da educação. Trad. Manoela Vaz. Lisboa: Relógio D’Água Editores, 1999. 
DELORY-MOMBERGER, Christine. Abordagens metodológicas da pesquisa biográfica. In: Revista Brasileira de Educação. Rio de Janeiro, v. 17, n. 51 set/dez, 2012b. p. 523-740.

DELORY-MOMBERGER, Christine. Biografia e educação: figuras do indivíduo-projeto. Tradução de Maria Passeggi, João Gomes da Silva Neto, Luís Passeggi. São Paulo: Paulus, Natal: EDUFRN, 2008.

DELORY-MOMBERGER, Christine. Vocabulaire des Histoires de Vie et de la Recherche Biographique. Toulouse: Érès.

DILTHEY, Wilhelm. Introdução às ciências humanas -Tentativa de uma fundamentação para o estudo da sociedade e da história. Trad. de Marco Antônio Casanova. São Paulo: Forense Universitária, 2010.

DOMINICÉ, Pierre. L'histoire de vie comme processus de formation. Paris: L'Harmattan, 2000.

FERRAROTTI, Franco. História, história de vida. O método biográfico nas Ciências Sociais. Tradução Carlos Galvão Braga e Maria da Conceição Passeggi. Natal: EDUFRN, 2012.

GADAMER, Hans Georg. Le problème de la conscience historique. Paris: Éditions du Seuil, 1996.

GADAMER, Hans Georg. Verdade e método I. Traços fundamentais de mais uma hermenêutica filosófica. Trad. Flávio Paulo Meurer. Brasil: Editora Universitária São Francisco, 1997.

JOSSO, Marie-Christine. Experiência de vida e formação. São Paulo: Paulus, Natal:Edufrn, 2010.

LABORIT, Emmanuelle, Le cri de la mouette, Paris: Robert Laffont, 1993.

PASSEGGI, Maria da Conceição. Enfoques narrativos en la investigación educativa brasileña. Revista Paradigma (Edición Cuadragésimo Aniversario: 1980-2020), Vol. XLI, p. 57-79, junio/2020. Disponível em:

http://revistaparadigma.online/ojs/index.php/paradigma/article/view/929. Acesso em: 15 ago. 2020.

PASSEGGI, Maria da Conceição. Reflexividad narrativa: "vida, experiencia vivida y ciência"; Márgenes Revista de Educación de la Universidad de Málaga, 1(3), 91-109. https://doi.org/10.24310/mgnmar.v1i3.9504

Disponível em: https://revistas.uma.es/index.php/mgn/article/view/9504

PASSEGGI, Maria da Conceição Narrativas da experiência na pesquisa-formação: do sujeito epistêmico ao sujeito biográfico. Roteiro, Joaçaba, v. 41, n. 1, p. 67-86, jan./abr. 2016.

Disponível em: https://portalperiodicos.unoesc.edu.br/roteiro/article/view/9267. Acesso em: 15 ago. 2020. 
PASSEGGI, Maria da Conceição. Experiência em formação. Educação. Porto Alegre, v. 34, n. 2, p. 147-156, maio/ago. 2011b. Disponível em:

https://revistaseletronicas.pucrs.br/ojs/index.php/faced/article/view/8697. Acesso em: 30 ago. 2020.

PINEAU, Gaston; Le Grand, Jean-Louis. As histórias de vida. Trad. Maria Passeggi; Carlos Braga. Natal: Edufrn, 2012.

PINEAU, Gaston. Emergência de um paradigma antropoformador de pesquisa-ação-formação transdisciplinar. Saúde e Sociedade, v.14, n.3, p.102-110, set./dez.2005. Disponível em: https://doi.org/10.1590/S0104-12902005000300006. Acesso em: 25 jul. 2020.

PRINCE, Gerald. Récit minimal et narrativité In: Le récit minimal: Du minime au minimalisme. Littérature, arts, médias [en ligne]. Paris : Presses Sorbonne Nouvelle, 2012 Disponível em : http://books.openedition.org/psn/190. Acesso em: 5 dez. 2020.

RICEEUR, Paul. Tempo e Narrativa, Tomos 1,2,3. São Paulos: Papirus, 1994.

SCHÖN, Donald. The reflective practitioner: how professionals think in action. New York: Basic Books, 1983.

TOURAINE, Alain. La société invisible. Regards (1974-1976). Paris: Éditions du Seuil, 1977.

\section{SOBRE A AUTORA:}

\section{Maria da Conceição Passeggi}

Doutora em Linguística pela Université de Montpellier 3, França. Professora dos Programas de Pós-Graduação em Educação da Universidade Federal do Rio Grande do Norte (UFRN) e da Universidade Cidade de São Paulo (Unicid). Líder do Grupo Interdisciplinar de PesquisaFormação, Representações e Subjetividade (GRIFARS) da UFRN, certificado pelo Conselho Nacional de Desenvolvimento Científico e Tecnológico (CNPq). Bolsista de produtividade CNPq - Pq1-D-Ed. E-mail: mariapasseggi@gmail.com

iD https://Orcid.Org/0000-0002-4214-7700 